\title{
O fã como leitor estético: uma análise das dimensões da competência midiática na fanfic Oitavo B de Malhação - viva a diferença
}

\author{
Daiana Sigiliano \\ Universidade Federal de Juiz de Fora, Programa de Pós Graduação em Comunicação, Juiz de Fora, MG, \\ Brasil \\ ORCID https://orcid.org/0000-0002-5163-9926
}

\section{Gabriela Borges}

Universidade Federal de Juiz de Fora, Programa de Pós Graduação em Comunicação, Juiz de Fora, MG, Brasil

ORCID http://orcid.org/0000-0002-0612-9732

\section{Resumo}

Ao criarem fanfics os fãs desenvolvem estratégias de escrita e comunicação relacionadas aos conteúdos multimodais e multimídia, além de novas formas textuais de conversação em rede. Esta leitura textual e intertextual do público ávido estabelece um nítido diálogo com o conceito de leitor semiótico/estético de Umberto Eco, em que as tramas exploram várias camadas interpretativas e vão além do paratexto. A partir desse aporte teórico, este artigo tem como objetivo analisar as dimensões da competência midiática, proposta por Ferrés e Piscitelli, que integram a fanfic Oitavo B. Publicada na plataforma Spirit Fanfics e Histórias, a história ressignifica o arco narrativo das personagens Lica (Manoela Aliperti) e Samantha (Giovanna Grigio), de Malhação - Viva a Diferença. Concluiu-se que a fanfic não só reforça e amplia a telenovela infantojuvenil, mas estabelece novas amarrações interpretativas.

\section{Palavras-chave}

Cultura de Fãs; Competência Midiática; Leitor

Semiótico/Estético; Fanfic; Malhação 


\section{Introdução}

O desenvolvimento dos estudos de fãs é marcado por três ondas ${ }^{1}$. Cada uma delas é definida a partir dos objetos estudados, dos pontos de referência conceitual e teórica e das orientações metodológicas (DUFFETT, 2013; GRAY; SANDVOSS; HARRINGTON, 2017; BOOTH, 2018). Porém, além das reflexões epistemológicas, as discussões do campo são também pautadas pela constante refutação da estigmatização do fã. De acordo com Sandvoss, Gray e Harrington (2017), as pesquisas de Fiske (1992), Jenkins (1992), BaconSmith (1992), Hills (2002, 2007), Sandvoss (2005), Booth (2010) e Duffett (2013) integram um importante processo de redefinição da identidade pública do fandom. Nesse contexto, os estudos se distanciaram da patologização que caracteriza o público ávido como imaturo, alienado e, principalmente, acrítico.

Conforme afirmam Jenson (1992), Jenkins (2015) e Duffett (2013), a abordagem negativa e estereotipada dos fãs permeia vários âmbitos, desde as raízes epistemológicas do termo até o modo como a subcultura era representada na mídia de massa. A palavra fã (fan no inglês) é uma abreviação de fanático (fanatic no inglês), da raiz latina fanaticus. Suas primeiras implicações estavam relacionadas ao entusiasmo excessivo, à devoção, à possessão, à insanidade e às falsas crenças voltadas para a religião e para a política. De acordo com Jenkins (2015), mesmo o termo sendo incorporado pela mídia no final do século XIX e popularizado pela imprensa esportiva, as conotações pejorativas continuaram sendo reverberadas.

A patologização da cultura dos fãs está presente em diversos âmbitos como, por exemplo, na televisão, no cinema e na literatura. No auge da franquia Star Trek, na década de 1970, o programa humorístico estadunidense Saturday Night Live (1975-atual, NBC) exibiu um esquete que satirizava de maneira pejorativa o fandom (JENKINS, 2015; SANDVOSS; GRAY; HARRINGTON, 2017). A sequência mostrava os trekkies² fazendo várias perguntas a William Shatner - que interpreta o Capitão Kirk na série Star trek (1966-1969, NBC). Irritado com a especificidade dos questionamentos, que falavam sobre o significado dos

\footnotetext{
1 De acordo com Sandvoss, Gray e Harrington (2017, p. 8-28) a primeira onda tinha como temas centrais as discussões sobre a representação e as relações de poder dos fãs, abrangendo o impacto econômico gerado pelo público ávido, a afetividade e as lógicas sociais das comunidades. A segunda onda destacava a complexidade e a multidimensionalidade das práticas e das comunidades de fãs, pautadas por diversas formas de participação e graus de engajamento, além da replicação de hierarquias sociais dentro das culturas e subculturas dos fandons (SANDVOSS; GRAY; HARRINGTON, 2017). Por fim, a terceira onda é marcada pela valorização dos fãs perante a indústria e a popularização das práticas dos fandons. Sandvoss, Gray e Harrington (2017) afirmam que as pesquisas de Hills (2007), Booth (2010) e Duffett (2013) exploram as nuances das comunidades em rede, das motivações pessoais dos fãs, além da relação com a identidade.

2 Nome dado aos fãs da franquia Star Trek.
} 
títulos dos episódios, a senha do cofre de Kirk vista em um frame e de personagens secundários, o ator grita com a plateia: "Olha só, pelo amor de Deus! Foi só um programa de TV!". A reação de Shatner deixa os "fãs" visivelmente magoados e constrangidos, como se seu envolvimento emocional e intelectual com a franquia se limitasse a uma obsessão infantilizada por trivialidades.

A suposta dificuldade do público ávido em separar a ficção da realidade também integrou outros estereótipos, principalmente no jornalismo e no cinema. Como explica Jenkins (2015, p. 32-33), “[...] as matérias jornalísticas caracterizavam os fãs como psicopatas cuja frustração na intimidade fantasiosa com as estrelas ou insatisfação do desejo de conquistar o estrelato tomam rumos violentos ou misantrópicos". Em outras palavras, a concepção estigmatizada do fã tinha como viés argumentativo a imagem de um sujeito emocionalmente instável e fora da realidade. 0 mito do fã "desequilibrado", segundo Jenkins (2015) e Duffett (2013), serviu de mote para longas-metragens como, por exemplo, o O fã obsessão cega (The fan, no original), de 1981, que tem como principal arco narrativo o amor doentio de Douglas Breen (Michael Biehn) por Sally Ross (Lauren Bacal). Na trama, o "fã" frustrado por não ter sua paixão correspondida rapta o ídolo e a ameaça de estupro e morte. Espectros semelhantes podem ser observados em Escuridão da morte (Fade to black, no original) de 1980, Louca obsessão (Misery, no original) de 1992, entre outros.

No gênero da comédia, a patologização do fã era abordada sob o viés do personagem solitário, sempre à margem das situações, como nos longas-metragens Ali Babá é boa bola (Ali Baba Goes to town, no original) de 1937, Stoogemania de 1986 e Sonhos de um sedutor (Play it again, Sam!, no original) de 1972. Segundo Jenkins (2015, p. 34), assim como “[...] opostos nos filmes dramáticos, esses homens levam vida ingrata, têm poucos laços sociais, relacionamentos românticos frustrados ou perigosos, emprego caótico ou humilhante, geralmente na periferia do show business". Outro estereótipo propagado pela mídia estava relacionado à figura feminina (JENSON, 1992; DUFFETT, 2013). Ao contrário do fã psicótico e do fã cômico, geralmente associado aos homens, o fã erotizado era explorado através das groupies. No livro Starlust: secret life of fans (1985), Fred Vermorel defende que as fãs têm um desejo súbito de possuir e serem possuídas pelos seus ídolos. 0 mito da fã orgástica objetificava a mulher, que além de estar sempre à disposição da estrela do cinema, da TV ou da música, proporcionava um espetáculo erótico para o público masculino.

Em contrapartida às questões conceituais, teóricas e metodológicas propostas nas três ondas discutidas por Sandvoss, Gray e Harrington (2017) e Duffett (2013), muitas 
pesquisas acadêmicas realizadas entre 1970 e 1990 se referiam aos fãs como "os outros", estabelecendo uma distinção, mesmo que velada, entre o trabalho sério, crítico e o fandom alienado e acrítico (JENKINS, 2015; GRECO, 2016). A abordagem gerava análises equivocadas, que não contemplavam a complexidade das práticas da cultura de fãs e corroboravam os estereótipos propagados pela mídia.

Como acadêmico, fico consternado com teorias generalistas sobre a audiência televisiva que dão pouca atenção à especificidade e complexidade das práticas que experiencio ${ }^{3}$ como fã. Fico igualmente perturbado com a forma inadequada com que muitos acadêmicos escrevem sobre cultura popular e em particular da nossa incapacidade de vincular a crítica ideológica ao reconhecimento do prazer que temos com esses textos populares. (JENKINS, 2015, p. 28).

Na contemporaneidade os estudos sobre a cultura de fãs exploram o engajamento crítico, produtivo e criativo do público ávido (SANDVOSS; GRAY; HARRINGTON, 2017, BO0TH, 2018). As análises multidisciplinares abordam, de modo geral, questões ligadas à comunicação, à criatividade, ao conhecimento e ao poder organizacional e cívico (BENNETT, 2014).

Discutida por Black (2006), Jenkins et al. (2009), Hirsjärvi (2013), Herrero-Diz et al. (2017) e Scolari (2018), o campo de estudos da competência midiática ${ }^{4}$ explora perspectivas relacionadas à compreensão crítica e à produção criativa dos fãs. Segundo Hirsjärvi (2013), as práticas dos fãs estimulam o desenvolvimento de novas possibilidades de aprendizado. A autora pontua que ao analisarmos as atividades de um fandom podemos observar uma multiplicidade de competências em operação como, por exemplo, a produção de conteúdo, o ativismo, a sistematização e a curadoria de informações, a ressignificação das tramas, a edição de imagens, entre outras.

A partir desse aporte teórico, este artigo tem como objetivo analisar as dimensões da competência midiática que integram a fanfic Oitavo B. Publicada na plataforma Spirit fanfics e histórias, a trama ressignifica o paratexto do arco narrativo das personagens Lica (Manoela Aliperti) e Samantha (Giovanna Grigio), da telenovela infantojuvenil Malhação viva a diferença (2017-2018) veiculada pela Rede Globo no horário das 17h55. A

\footnotetext{
3 Jenkins é declaradamente um aca-fan, um acadêmico e também fã. Ao pesquisar Star Trek, no livro Invasores do texto (2015), o pesquisador relata a sua visão como integrante ativo do fandom da franquia. Seu site, que reúne suas pesquisas e insights, é intitulado Confessions of an aca-fan (Confissões de um aca-fan no português).

4 Neste trabalho iremos adotar a definição de Ferrés e Piscitelli (2015), segundo os autores a competência midiática é uma combinação de conhecimentos, habilidades e atitudes consideradas necessárias para um contexto determinado.
} 
metodologia proposta por Ferrés e Piscitelli (2015) abrange seis dimensões (linguagem, ideologia e valores, estética, tecnologia, processos de interação e de produção e difusão), cada uma delas está relacionada ao modo como o público recebe, interage e produz os conteúdos midiáticos. Neste trabalho iremos refletir sobre três dimensões, a linguagem, a ideologia e valores e a estética, a fim de discutir o desenvolvimento da competência midiática na produção de fanfics.

\section{Lendo textualmente e intertextualmente: as estratégias de interpretação dos fãs}

Para Eco (2002) as obras pós-modernas são compostas por uma dupla codificação. 0 termo se refere, segundo o autor, a textos híbridos que imbricam conotações populares e estilísticas ao mesmo tempo. 0 conceito foi cunhado pelo arquiteto Charles Jencks, em 1977, para designar uma combinação de técnicas na arquitetura que possibilitava que a obra fosse compreendida em dois níveis simultaneamente, ou seja:

[...] dirigindo-se aos outros arquitetos e a uma minoria que entende de significados arquitetônicos específicos, mas também ao público mais amplo ou aos habitantes do lugar, os quais se interessam por outras coisas, como a comodidade do edifício [...]. (JENCKS, 1977, p. 14-15, tradução nossa)..$^{5}$

Entretanto, Eco (2002) afirma que a dupla codificação de Jencks (1977) vai além do viés arquitetônico e pode ser observada na música, na literatura, nos spots publicitários, entre outros âmbitos. A partir da ampliação do termo, o autor propõe o conceito de ironia intertextual. Para explicar a ironia intertextual, Eco (2002) usa como exemplo sua obra $O$ nome da rosa. Segundo o autor, em um dos intertítulos ${ }^{6}$ do livro ele faz uma referência ao escritor e poeta italiano Manzoni. Porém, a alusão não prejudica a compreensão da frase, isto é, os leitores que não perceberem a intertextualidade irão entender o sentido geral da frase, já os que observarem a referência terão uma experiência mais dinâmica do texto.

\footnotetext{
5 No original: "addressing other architects and a minority who understand specific architectural meanings, but also the wider public or local inhabitants, who are interested in other things, such as the comfort of the building" (JENCKS, 1977, p. 14-15).

${ }^{6} 0$ autor se refere ao intertítulo "Naturalmente, um manuscrito". Neste caso, o "naturalmente" é uma referência à obra de Manzoni.
} 
[...] quem entende a alusão estabelece uma relação privilegiada com o texto (ou a voz narradora), quem não entende segue adiante da mesma forma - e terá diante de si dois caminhos: ou entende por virtude própria que aquele manuscrito só pode ser um artifício literário [...] ou, como muitos fizeram, escreverá me perguntando se aquele manuscrito tão fascinante existe realmente. (ECO, 2002, p. 204).

Eco (2002) ressalta que a obra pode ter referências externas e não, necessariamente, apresentar ironia intertextual. Como, por exemplo, o livro The Waste Land (1922) em que o autor T. S. Eliot inseriu notas explicativas para cada alusão, detalhando as camadas interpretativas para todos os leitores. Apesar da dupla codificação e da ironia intertextual transmitirem múltiplos significados simultaneamente, o que as diferencia é o modo de produção de sentido, como explica Eco (2002):

[...] no double coding arquitetônico, o visitante pode não se dar conta de que uma colunata com um tímpano está citando a tradição grega e goza igualmente da harmonia, da multiplicidade ordenada daquela construção. Ao contrário [na ironia intertextual], o leitor que não percebe o meu 'naturalmente', sabe apenas que está lendo um manuscrito, mas perde a remissão e a afetuosa ironia. (ECO, 2002, p. 205).

Nesse contexto, a ironia intertextual "[...] seleciona, e privilegia os leitores intertextualmente avisados, embora não exclua os menos avisados" (ECO, 2002, p.205). Com base nas discussões sobre dupla codificação e ironia intertextual, Eco (2002) elabora dois níveis de leitura. 0 leitor de primeiro nível deseja saber somente como a história vai acabar. De acordo com o autor, o leitor semântico está interessado, por exemplo, se Ahab, de Moby dick, livro publicado em1851, conseguirá capturar a baleia, ou, se Pinóquio, de As aventuras de Pinóquio de 1881, vai se transformar em um menino de carne e osso. Ou seja, o seu foco é direcionado para os desdobramentos dos arcos narrativos das tramas. 0 leitor de segundo nível "[...] se pergunta que tipo de leitor aquele conto pede que ele seja, e quer descobrir como procede o autor modelo que o instruiu passo a passo" (ECO, 2002, p. 208). Em suma, o leitor semântico quer saber o que irá acontecer na história, já o leitor semiótico/estético como aquilo que acontece foi narrado (ECO, 2002, p. 208).

É importante ressaltar que não existem leitores exclusivamente de segundo nível, isto é, para ser um leitor semiótico/estético é preciso ser, mesmo que inicialmente, um leitor semântico. Segundo Eco (2002, p. 208), "Para saber como a história acaba, geralmente basta ler uma única vez. Para transformar-se em leitor de segundo nível é preciso ler muitas vezes, 
e certas histórias deve-se lê-las ao infinito". Dessa forma, o leitor de segundo nível é aquele que está a par das nuances do texto, dos detalhes narrativos, que está interessado na linguagem e consegue identificar a ironia intertextual.

Os níveis de leitura propostos por Eco (2002) sistematizam as estratégias de interpretação dos fãs e nos ajudam a refletir sobre a compreensão crítica e a produção criativa desta comunidade de subcultura no campo da competência midiática. De acordo com Jenkins (2015, p. 70), a leitura ${ }^{7} \tilde{a}^{8}$ é "[...] um processo, um movimento que vai da recepção inicial da transmissão televisiva a uma elaboração gradual dos episódios e sua remodelagem em termos alternativos". Nesse contexto, o fã dominaria dois modos de leitura: a textual e a intertextual (JENKINS, 2015). Ao ler textualmente o público ávido estabelece uma relação íntima com o universo ficcional, reconhecendo cada detalhe do metatexto9. 0 segundo modo de leitura é a intertextual e vai além da trama, nela o fã consegue identificar múltiplas redes intertextuais entre o paratexto em questão e os elementos externos, formando amarrações interpretativas.

As estratégias de interpretação dos fãs têm como um de seus pontos norteadores a reprise. Segundo Barthes (1992), reler um texto altera profundamente a experiência do leitor com uma narrativa. Como pontua o autor, "[...] reler remove o texto de sua cronologia interna ('isto acontece antes ou depois daquilo') e recaptura um tempo mítico (sem antes ou depois)" (BARTHES, 1992, p. 19). Ao assistir a um conteúdo novamente, o interesse do fã passa a ser outro como, por exemplo, os significados temáticos, as entrelinhas, o contexto social do autor (JENKINS, 2015). "O livro relido não é uma obra que encontramos à primeira leitura; é 'o mesmo e novo'”. (JENKINS, 2015, p. 82). Dessa forma, o fã seria o leitor semiótico/estético proposto por Eco (2002), compreendendo criticamente o universo ficcional e suas amarrações interpretativas.

Esse processo de leitura semiótica/estética estimula a ressignificação dos conteúdos, em que o público ávido explora novas perspectivas e linguagens da trama. De acordo com Jenkins (2015), ao compreender a história textualmente e intertextualmente o fandom consegue "[...] reconhecer os ruídos do texto, seus lapsos narrativos, seus detalhes excessivos, suas pontas soltas e contradições - e encontra aberturas para a elaboração de

7 Fannish reading na versão em inglês.

8 É importante frisar que neste artigo estamos nos debruçando sobre os fãs midiáticos. Para Evans e Stasi (2014, p. 7) esta subseção dos estudos de fãs abrange os fãs de música, de esportes, de celebridades, de itens de consumo e, principalmente, de cinema e de televisão.

9 De acordo com Jenkins (2015) o metatexto se baseia em informações fornecidas especificamente pelo programa e em fontes secundárias (jornais, sites especializados, entrevistas com o autor e com o elenco etc.). 
seu mundo e especulações quanto a suas personagens" (JENKINS, 2015, p. 89). É a partir destas estratégias de interpretação que se estabelecem as práticas da cultura de fãs, tais como os vídeos on rrack $^{10}$, os perfis fictícios de personagens nas redes sociais, as fanfics etc. Porém, é importante ressaltar que "[...] o fandom é realizado de maneira diferente e pode significar diversas coisas em distintos microcontextos, em diferentes momentos de interação social, e até mesmo em plataformas distintas" (HILLS, 2015, p. 149).

Desta forma, as práticas dos fãs devem ser analisadas considerando sua multiplicidade e idiossincrasias. Em outras palavras, a compreensão crítica e a produção criativa desta comunidade de subcultura, mesmo partindo de um único mundo ficcional, podem apresentar significáveis variações nas estratégias de interpretação.

\section{Fanfic: do paratexto a ressignificação}

A fanfic abrange "[...] qualquer narração em prosa com histórias e personagens extraídos dos meios de comunicação" (JENKINS, 2009, p. 380). Esta prática popular na cultura de fãs pode ser inspirada tanto em universos ficcionais (filmes, séries, livros etc.) quanto em pessoas reais ${ }^{11}$ (integrantes de bandas, atrizes, atores etc.). Como explica Jamison (2017, p. 31), “[...] hoje entendemos a fanfiction basicamente como uma escrita que continua, interrompe, reimagina ou apenas faz alusão a histórias e personagens que outras pessoas já escreveram". Os registros iniciais das fanfics antecedem a década de 1930, quando as histórias produzidas pelos fãs circulavam por meio de pulp magazines e fanzines (JAMISON, 2017). No âmbito das narrativas ficcionais seriadas televisivas, a série Star Trek foi responsável pela popularização das tramas (JENKINS, 2015; JAMISON, 2017). Os fãs exploravam distintas perspectivas da atração, entre elas o emblemático romance fictício $\left(\right.$ slash $\left.^{12}\right)$ entre os personagens Kirk e Spock.

A criação, a publicação e o compartilhamento das fanfics ganharam novas possibilidades no ambiente da convergência midiática. De acordo com Jamison (2017) e Coppa (2017), a cultura digital ampliou as formas de engajamento que já eram recorrentes nos fandons.

\footnotetext{
${ }^{10}$ Considerado um dos tipos de remix mais produzidos pelos fãs, o crack mistura sequências da história com músicas, memes e outros conteúdos audiovisuais.

11 Conhecida como Real Pearson Fic (RPF).

12 Romance homoerótico, normalmente entre personagens heterossexuais (JAMISON, 2017, p. 94).
} 
[...] os fãs sempre foram os impulsionadores da tecnologia e já se comunicavam entre si por meio de toda plataforma concebível [...]. 0 crescimento de softwares de mídia social estilo Web 2.0 certamente facilitou a participação em fandom: agora qualquer um poderia criar uma página apenas se inscrevendo numa rede; quando antes isso exigia habilidade, assim como espaço em servidor. (COPPA, 2017, p. 295).

A fanfic materializa o senso de coletividade do fandom por meio da troca que se estabelece entre os autores e os leitores, desde o desenvolvimento da história até a sua publicação.

A recepção dos fãs não pode existir e não existe isolada, mas é sempre moldada através das opiniões de outros fãs e motivada, pelo menos em parte, pelo desejo de maior interação com uma comunidade social e cultural mais ampla. (JENKINS, 2015, p. 90).

Na cultura da convergência esse processo coletivo se torna mais plural, instantâneo e acessível. Além das potencialidades criativas e colaborativas das redes sociais e dos sites de compartilhamento de conteúdo legal e ilegal, as plataformas destinadas, especificamente, à publicação de fanfics apresentam uma arquitetura operacional ${ }^{13}$ com várias funções que estimulam a reflexão crítica dos fãs.

No Brasil os sites Nyah! Fanfiction e Spirit Fanfics e Histórias reúnem cerca de um milhão de fanfics sobre os mais variados temas. Além da publicação das histórias, os fãs podem ler outras fanfics, postar comentários e criar listas de leitura. Também é possível acessar lições online com dicas de gramática e de construção narrativa. Um ponto interessante no processo colaborativo destas plataformas são os papéis de Beta e de Capista. Classificados por Jamison (2017) como 'leitores beta de validação' estes fãs atuam como editores de algumas fanfics. A partir de um processo seletivo proposto por cada site, os interagentes ${ }^{14}$ são nomeados e realizam a pré-aprovação dos capítulos antes deles serem publicados online. Segundo a autora, "Todo o trabalho deles é voluntário e é um trabalho real. Eles dedicam tempo e atenção à tarefa e, como muitos deles não escrevem, não recebem o mesmo serviço em troca" (JAMISON, 2017, p. 274). Já os capistas ajudam na criação de capas para as fanfics e/ou capítulos, as imagens são solicitadas gratuitamente

\footnotetext{
${ }^{13} \mathrm{~A}$ arquitetura operacional abrange a forma de funcionamento (sistema operacional, interface e configuração) e de acessibilidade (modo de interação intuitiva, desenvolvimento e disponibilidade de aplicações) de um dispositivo e/ou plataforma.

14 Participantes da interação (PRIMO, 2007).
} 
através das próprias plataformas. Geralmente as capas são compostas por fotos que fazem alusão ao principal arco narrativo da trama e informações tais como título, autor etc.

De acordo com Thomas (2007) e Tirocchi (2018), as plataformas digitais nas quais as fanfics são publicadas e lidas estimulam o desenvolvimento da competência midiática ${ }^{15}$. Os autores afirmam que ao compartilharem suas produções os fãs desenvolvem estratégias de escrita e comunicação relacionadas aos conteúdos multimodais e multimídia, além de novas formas textuais de conversação em rede. Além do estímulo à compreensão crítica das mídias digitais e do ambiente da convergência, a fanfic parte de um profundo entendimento do fã sobre os universos ficcionais (JENKINS, 2012; ALVES, 2014; GROSSMAN, 2017; SCOLARI, 2018).

Escrever e ler fanfiction não é apenas algo que você faz; é uma forma de pensar criticamente sobre a mídia que você consome, de estar consciente de todas as suposições implícitas que um trabalho canônico carrega, e de considerar a possibilidade de que aquelas suposições poderiam não ser as únicas possíveis (GROSSMAN, 2017, p. 13).

Como discutimos anteriormente, ao ser um leitor semiótico/estético o fã, por meio de suas estratégias de interpretação, é capaz de identificar as contradições, as potencialidades, as lacunas, entre outros aspectos dos universos ficcionais. Nesse contexto, é a partir desta interpretação crítica que se dá a produção criativa das fanfics. Todos os desdobramentos narrativos da história, por mais amplos que sejam, devem indicar que aquela trama poderia ter acontecido de forma plausível no paratexto. De acordo com Jenkins (2012):

É certo que existem histórias ruins que não se aprofundam nos personagens ou caem em interpretações banais, mas a boa fan fiction mostra um profundo respeito pelo que gerou a fagulha na imaginação ou curiosidade do escritor-fã. Fan fiction é especulativa, mas também é interpretativa. E mais que isso, é criativa. 0 escritor-fã quer criar uma nova história que diverte por si só e a oferece para quem talvez seja a plateia mais exigente que se poderia imaginar - outros experts extremamente investidos na obra original. (JENKINS, 2012, p. 20).

Ao reimaginar os universos ficcionais, o fã também reflete sobre os significados sociais e culturais implícitos nos conteúdos midiáticos, tais como: os estereótipos, as

15 Também conceituado como e-literacy (LUKE, 2007). 
questões relacionadas à diversidade e à representatividade. Segundo Jamison (2015), as histórias estimulam a experimentação de novos estilos literários e técnicas de escrita do público ávido.

No âmbito da ficção seriada televisiva nacional, a produção das fanfics de telenovelas abrange tanto o público adulto quanto o infantojuvenil. Esta prática da cultura de fãs no Brasil foi consideravelmente potencializada pela disponibilização - legal e ilegal - dos capítulos online, possibilitando que os programas fossem reassistidos (JACOB et al., 2015). Segundo Jacob et al. (2015), de modo geral, as ficções produzidas pelo fandom dos folhetins exploram interlúdios do paratexto, reescritura das cenas, finais alternativos, reapresentação dos personagens e mudanças de ambientação. Os autores também afirmam que os fãs tendem a abordar histórias protagonizadas por casais, ampliando e reimaginando pontos nodais do arco narrativo como, por exemplo, o primeiro beijo, o pedido de casamento, entre outros.

Criada por Cao Hamburger e vencedora do Emmy Internacional Kids, a vigésima quinta temporada de Malhação (Rede Globo, 1995-atual), intitulada Malhação: viva a diferença (2017-2018), bateu recordes de audiência e promoveu a discussão de temas até então inéditos na trama (VIEIRA, 2018). Pela primeira vez, em 25 anos de exibição, a atração infantojuvenil foi protagonizada por cinco mulheres. As adolescentes Keyla (Gabriela Medvedovski), Benê (Daphne Bozaski), Tina (Ana Hikari), Lica (Manoela Aliperti) e Ellen (Heslaine Vieira), de origens e personalidades diferentes, ficam presas no mesmo vagão de metrô durante uma pane elétrica. A personagem Keyla entra em trabalho de parto e as adolescentes se unem em solidariedade para ajudá-la no nascimento do bebê. Em 2020, o universo da trama foi expandido no spin-off As Five (2020-atual) no Globoplay. Na série, as personagens se reencontram após seis anos sem se verem e enfrentam conflitos comuns à Geração Z. Entre os temas abordados nos episódios estão o feminismo, o preconceito, a xenofobia, o capacitismo e a maternidade solo.

Um dos arcos narrativos mais populares entre o público envolveu as personagens Lica e Samantha (Giovana Grigio), intitulado pelo fandom como Limantha, o ship ${ }^{16}$ é o acrônimo dos nomes das adolescentes. Ao longo dos capítulos de Malhação os telespectadores ${ }^{17}$ interagentes produziram fanarts, perfis fictícios, vídeos on crack, memes e, principalmente, fanfics. Nas plataformas Spirit fanfics e Histórias, Nyah! fanfiction e no

\footnotetext{
16 Ship é o nome designado ao casal que o público gostaria de ver junto, chamado de casal shippado (JAMISON, 2017).

${ }^{17} 0$ termo telespectador interagente é usado neste artigo para designar o público que interage (propaga, retuíta, produz conteúdo, responde às enquetes etc.) com o universo ficcional das séries televisivas (SIGILIANO; BORGES, 2017)
} 
WattPad foram publicadas cerca de $381^{18}$ histórias durante o período de exibição da telenovela, gerando cerca de 973 mil visualizações ${ }^{19}$. As fanfics criadas pelos fãs aprofundavam os arcos narrativos de Lica e Samantha e exploravam os desdobramentos que não estavam presentes no universo ficcional.

\section{Análise das dimensões da competência midiática}

Para operacionalizar metodologicamente o uso do conceito de competência midiática, Ferrés e Piscitelli (2015) definiram seis dimensões a partir das quais os indicadores são elaborados. São elas: linguagem, ideologia e valores, estética, tecnologia, processos de interação e de produção e difusão. Dessa forma, estes indicadores se relacionam tanto ao âmbito de análise, isto é, a forma como as pessoas recebem e interagem com as mensagens, quanto ao âmbito de expressão, o modo como as mensagens são produzidas pelas pessoas. Porém, é importante ressaltar que os pontos teorizados pelos autores estão interrelacionados, ou seja, esta separação é feita para que possamos analisar didaticamente cada uma delas.

Neste trabalho iremos aprofundar três dimensões: linguagem, ideologia e valores e estética. Entretanto, as outras dimensões também estão presentes. A tecnologia permeia toda a relação dos fãs com o ambiente digital. Os processos de interação podem ser observados na interação feita na seção de comentários e nas redes sociais, e nos conteúdos produzidos a partir de múltiplas camadas interpretativas. Os processos de produção e difusão abrangem a curadoria e a ressignificação do metatexto.

A fanfic Oitavo B, foi criada pelo user UmaOtaku-chan e publicada na plataforma Spirit fanfics e Histórias. A história é composta por 40 capítulos de em média 15 mil palavras cada um. Segundo as métricas do site, a trama foi postada durante a exibição de Malhação viva a diferença no dia 31 de janeiro de 2018 e integra a lista de leitura de 220 usuários. Os capítulos foram visualizados 85.553 vezes, gerando uma média de 874 comentários.

De acordo com a sinopse disponibilizada no Spirit a fanfic, a narrativa parte da seguinte premissa: "Samantha odeia histórias de amor e, particularmente, nunca acreditou muito nessa de "amor". Quando a garota mais popular se vê diante da "nova" aluna, ela se

\footnotetext{
18118 (Spirit fanfics), 24 (Nyah! fanfiction) e 239 (WattPad), totalizando 381 histórias.

${ }^{19}$ Consultado em: 27 de junho de 2019.
} 
percebe que talvez, só talvez, o amor possa existir" (OITAVO B, 2018). A seguir (Figura 1) exemplificamos a fanfic com uma arte ilustrativa de Oitavo $B$ :

Figura 1 - Imagem principal da fanfic Oitavo $B$

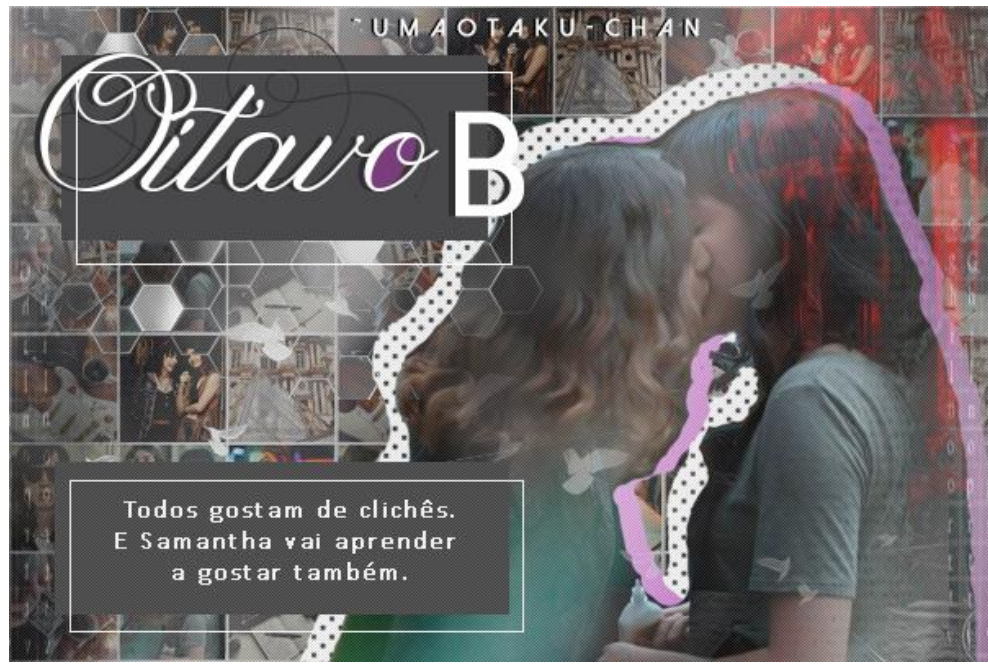

Fonte: Umaotaku-Chan (2019).

A trama tem como fio condutor o relacionamento de Lica e Samantha e explora os principais acontecimentos da vida do casal, tais como: o primeiro beijo, como elas se conheceram, as brigas, entre outros. Os desdobramentos da história são apresentados ao leitor a partir do ponto de vista de Lica, com a personagem contando para as filhas a sua história de amor com Samantha. Entretanto, ao longo dos capítulos, outras perspectivas e eu-líricos são explorados na fanfic. Oitavo $B$ é composta por vários elementos que aproximam os leitores adolescentes da história como, por exemplo, referências da cultura pop (filmes e programas de TV), reproduções de mensagens de texto do aplicativo WhatsApp e trechos de músicas.

De acordo com Ferrés e Piscitelli (2015), a dimensão da linguagem se refere à capacidade de interpretar, avaliar, analisar, expressar e modificar os conteúdos existentes. 0 âmbito da análise está relacionado com a habilidade de compreender a forma como as mensagens são construídas em diferentes mídias, gerando diferentes produções de sentido, além da capacidade de estabelecer relações entre textos, códigos e mídias. 0 âmbito da expressão se refere à capacidade que o sujeito tem de se expressar utilizando diferentes sistemas de representação e estilos em função da situação comunicativa, do conteúdo 
transmitido e do interlocutor, além da capacidade de modificar os produtos existentes, conferindo-lhes novos significados.

O processo de ampliação do paratexto por meio desta prática da cultura de fãs já apresenta um nítido diálogo com a dimensão da linguagem. Ou seja, os arcos narrativos de Oitavo $B$ foram estruturados a partir da interpretação crítica do user UmaOtaku-chan, identificando os potenciais, as contradições e as lacunas. Nesse contexto, mesmo ampliando e ressignificando a trama de Malhação, o desenvolvimento da fanfic parte de um conhecimento apurado da fã ${ }^{20}$ sobre o universo ficcional da telenovela.

A capacidade de modificar os conteúdos existentes destacada por Ferrés e Piscitelli (2015) pode ser observada em diversos trechos de Oitavo B. Ao longo dos 40 capítulos, a fã reproduz diálogos do folhetim na íntegra. Entretanto, os trechos são explorados em contextos narrativos diferentes dos presentes na atração. Como, por exemplo, a conversa entre Lica e Samantha em que as adolescentes flertam enquanto estudam para a prova de física. Apesar de UmaOtaku-chan não alterar as falas das personagens, a fã insere a sequência em situações distintas e a mudança abrange aspectos como a ambientação, o desdobramento da conversa e as consequências do plot $^{21}$. Nesse sentido, o leitor tem acesso a uma espécie de versão alternativa do diálogo exibido na TV. A Oitavo B também apresenta novas perspectivas dos arcos narrativos, pois, grande parte da fanfic é contada a partir do ponto de vista de Lica. Dessa forma, é possível compreender os sentimentos e intenções da adolescente. Em alguns capítulos, os acontecimentos também são relatados por outros personagens da trama. Como, por exemplo, quando Samantha conta sobre a morte dos pais e o acidente de Clara (Isabella Scherer).

Além da ressignificação do universo ficcional de Malhação, a trama é permeada por elementos intertextuais. Os capítulos são compostos por camadas interpretativas que vão além do arco narrativo protagonizado por Lica e Samantha. Ao lermos a fanfic, é possível observar constantes citações de memes como, por exemplo, "às vezes o indivíduo está louco na droga", "já se hidratou hoje?", "quer o mundo? eu te dou!", “Deus me dibre, mas quem me dera". As referências ampliam a produção de sentido das cenas e também aproximam os temas abordados dos leitores adolescentes.

Como será detalhado na dimensão da estética, os desdobramentos da fanfic, em sua grande maioria, são intercalados por trechos de músicas. As canções, de artistas como

\footnotetext{
${ }^{20}$ Em seu perfil na plataforma, UmaOtaku-chan se identifica com o gênero feminino.

${ }^{21}$ História da série ou da temporada ligada ao principal arco narrativo.
} 
Camila Cabello, Blink-182, Nomy, Demi Lovato, EDEN e Imagine Dragons, são usadas pela fã como recurso narrativo. Isto é, durante as sequências as personagens citam trechos das músicas para explicitarem seus sentimentos, medos e inseguranças. Os elementos intertextuais de Oitavo $B$ também abrangem obras literárias, séries estadunidenses e a cultura pop. Como, por exemplo, quando Lica faz uma analogia entre Samantha e Capitu, de Dom Casmurro (Machado de Assis, 1899), e as comparações entre as situações vividas pelas adolescentes e as personagens dos programas Grey's anatomy (2005-atual, ABC) e Glee (2009-2015, Fox). Tais como "Eu não tenho culpa se você está pagando de mãe da Meredith Grey, meu cheiro" e "Mas sério, eu me sinto dentro da série Glee e a Samantha é a Quinn Fabray da primeira season antes da gravidez". Além disso, o fandom de Limantha é constantemente citado por UmaOtaku-chan, em diversos capítulos a fã faz referências a piadas internas e provoca outros ships da telenovela.

$O$ universo ficcional de Oitavo $B$ não se limita a vigésima quinta temporada de Malhação. No capítulo 12, os personagens de Malhação: intensa como a vida (2012-2013, Rede Globo) são inseridos na fanfic. Na trama criada pela fã, K1 (Talita Younan) é prima de Fatinha (Juliana Paiva). o crossover acontece durante uma festa em que Lica, Samantha e seus amigos do colégio Grupo estão presentes. Apesar de não interferirem diretamente nos desdobramentos da história, os programas Chiquititas (2013-2015, SBT) e 3 Teresas (20132014, GNT), ambos protagonizadas por Manoela Aliperti e Giovanna Grigio, respectivamente, também são citados por UmaOtaku-chan.

Segundo Ferrés e Piscitelli (2015), a dimensão da ideologia e dos valores envolve a capacidade dos interagentes de repercutir de forma crítica o modo como as representações midiáticas estruturam a nossa percepção da realidade; a habilidade de detectar, contrastar, buscar e avaliar as intenções e interesses presentes nos conteúdos; a capacidade de analisar criticamente as produções, identificando estereótipos; bem como gerir as próprias emoções, identificando o potencial mecanismo de manipulação das telas. 0 âmbito da expressão relaciona-se com a capacidade de usar as novas mídias para se comprometer como cidadão, além de elaborar e modificar produtos para questionar valores ou estereótipos presentes nas produções midiáticas.

A dimensão da ideologia e dos valores proposta pelos autores, está presente de maneira mais ampla na escolha do casal Lica e Samantha como protagonistas da fanfic Oitavo B. As adolescentes formaram, em 23 anos de exibição, o primeiro casal bissexual de Malhação. Nesse sentido, ao optar entre todos os personagens da temporada e os diversos 
casais pelo ship Limantha, a fã ressalta, mesmo que indiretamente, a sua predisposição em refletir, questionar e modificar os valores e os estereótipos presentes na telenovela. Isto é, ao longo dos 40 capítulos, o user UmaOtaku-chan não só ressignifica o paratexto, mas amplia e reforça as questões ligadas à sexualidade e à representação das adolescentes.

Um dos pontos centrais de Oitavo B é o romance de Lica e Samantha e o erotismo que envolve este relacionamento. Nesse contexto, cada carícia é descrita com detalhes, o sexo é destacado em quase todos os capítulos. Porém, apesar da temática ser recorrente nessa prática da cultura de fãs, no caso da fanfic analisada, a ampliação desse arco narrativo também está relacionada com o modo como o namoro das personagens foi abordado na TV.

Ao explorar a sexualidade de Limantha, o user UmaOtaku-chan insere questões que não poderiam ser tratadas no horário de exibição de Malhação e que foram criticadas pelo fandom. Uma das reclamações dos telespectadores interagentes era que o casal não trocava carícias durante os beijos. No Twitter, o público repercutiu o fato das personagens heterossexuais se beijarem ardentemente, no entanto, Lica e Samantha eram representadas apenas com selinhos. Em Oitavo B, as sequências românticas são erotizadas, descrevendo sistematicamente cada toque, gesto e sensação. Enquanto o sexo ficava subentendido na telenovela, na fanfic as personagens tinham uma vida sexual ativa. 0 tópico era explorado não só entre Lica e Samantha, mas com os affairs das adolescentes.

As questões ligadas à orientação sexual das personagens também foram ampliadas pela fã. Nos capítulos da trama Lica reflete sobre os estereótipos e os preconceitos que sofre por ser bissexual, enquanto que, no paratexto, nem ela nem Samantha se assumem de fato. Nesse contexto, a fã usa a fanfic como ferramenta, considerando as limitações do conteúdo, de debate e conscientização de assuntos que ainda são vistos como tabus.

Oitavo $B$ também aprofunda a carga dramática dos dramas vividos pelas personagens, tais como o relacionamento familiar, o bullying, a automutilação, o suicídio e o consumo de drogas. Por ter o eu lírico em primeira pessoa os relatos sobre estas questões ficam mais pessoais e próximos do público. Na seção comentários dos capítulos da fanfic, podemos observar vários leitores, como na Figura 2, dizendo que se identificaram com os arcos narrativos e que a história os ajudava a superar problemas semelhantes. 
Figura 2 - Na seção de comentários do capítulo 21, uma leitora agradece a autora pelos temas abordados na fanfic

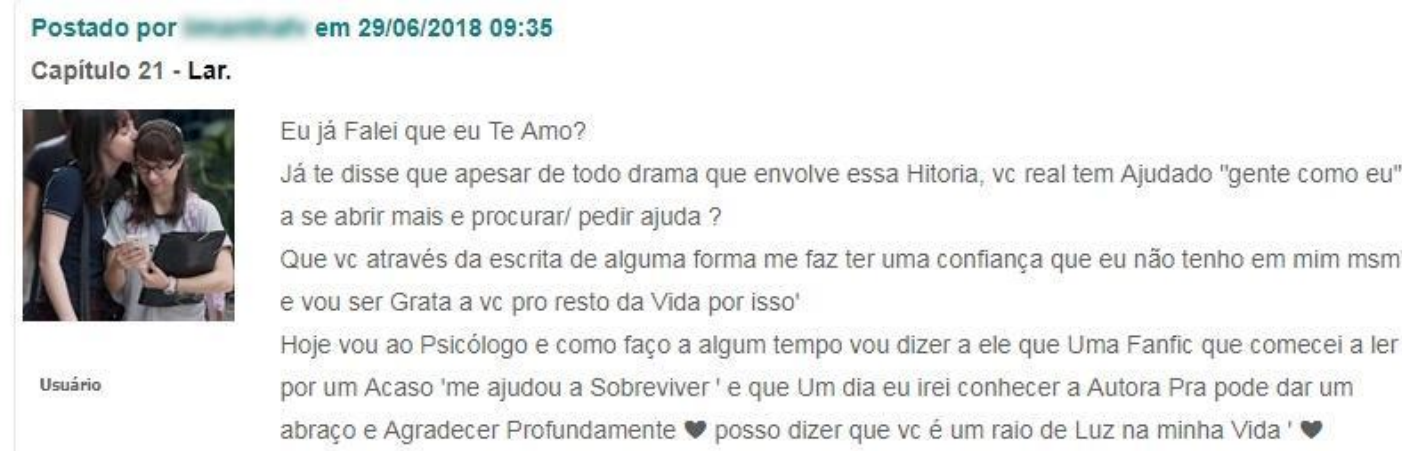

Fonte: Umaotaku-Chan (2019).

Apesar de toda carga dramática que envolve alguns acontecimentos da fanfic, a fã tem consciência de sua responsabilidade ao publicar uma história que trata de temas tão densos. Em diversos capítulos, UmaOtaku-chan justifica, nas seções de Notas do Autor e Notas Finais, a complexidade dos assuntos que são abordados. A fã recomenda que caso o leitor não se sinta confortável com os desdobramentos da trama que não leia o capítulo.

A dimensão da estética proposta por Ferrés e Piscitelli (2015) está relacionada ao entendimento da importância dos aspectos técnico-expressivos na composição da produção midiática. $\mathrm{O}$ âmbito da análise envolve a sensibilidade para reconhecer a qualidade estética dos conteúdos e a capacidade de identificar as categorias estéticas básicas, como a inovação formal e temática, a originalidade e o estilo. 0 âmbito da expressão está relacionado com a capacidade de produzir mensagens criativas, bem como se apropriar de produções artísticas e transformá-las, visando potencializar a criatividade, a experimentação e a sensibilidade estética.

Na sinopse da fanfic, a fã destaca os clichês das histórias de amor e a questão é retomada em alguns capítulos da trama. UmaOtaku-chan afirma, na seção Notas do Autor, que reconhece que certos recursos narrativos usados na fanfic são previsíveis, mas que o clichê faz parte do universo ficcional proposto por ela. Nesse sentido, a fã não só consegue identificar o elemento como também o insere na trama a fim de cumprir seu objetivo.

Outro ponto pertinente em Oitavo B são as reflexões sobre o âmbito das fanfics. Na seção Notas do Autor de alguns capítulos UmaOtaku-chan faz uma curadoria de histórias sobre o ship Limantha. Dessa forma, a fã incentiva que os leitores conheçam outras produções e ampliem o seu repertório. A metalinguagem também integra os capítulos de 
Oitavo B. Como, por exemplo, em Casa (capítulo 8) e Epílogo (capítulo 25) em que Lica alerta Samantha que ler fanfics é um caminho sem volta e, posteriormente, que a vida não é uma fanfic. Este recurso usado pela fã ganha mais pertinência dentro do universo ficcional da trama, no capítulo 15, UmaOtaku-chan apresenta um arco narrativo em que Tina escreve uma fanfic.

Ao longo dos 40 capítulos de Oitavo B, é possível observar a compreensão crítica que a fã tem da estrutura de uma narrativa. As mudanças cronológicas e a alternância de sequências e eu líricos é delimitada por recursos gráficos como itálico e negrito. 0 modo como UmaOtaku-chan usa a arquitetura operacional do Spirit está diretamente relacionado com a dimensão da estética. Na seção de comentários a fã estabelece um diálogo próximo com os seus leitores, além de agradecer a repercussão positiva da história, ela indica músicas para ouvir lendo os capítulos, comenta os acontecimentos de Malhação (quando a atração ainda estava no ar), pede sugestões para a cor das capas e adianta alguns detalhes dos capítulos que serão publicados. 0 mesmo acontece nas Notas do Autor e nas Notas Finais - espaço usado para divulgar outras fanfics, discutir sobre os capítulos da telenovela, e explicar aos leitores a estrutura narrativa da fanfic e seus principais desdobramentos, que na perspectiva da fã, podem gerar possíveis dúvidas nos leitores. Nas seções, UmaOtakuchan também compartilha o seu processo criativo. A fã detalha seus bloqueios criativos, a forma como se organiza para desenvolver os capítulos e como elabora os arcos narrativos. Nesse sentido, ao discutir e compartilhar o seu processo criativo, UmaOtaku-chan reflete sobre o seu modo de escrita e criação de Oitavo $B$.

0 universo ficcional da fanfic foi expandido em outras plataformas, tais como o WhatsApp, o Twitter e o Spotify. As contas eram gerenciadas pela fã e tinham a função de aprofundar a história de Lica e Samantha. No aplicativo WhatsApp, UmaOtaku-chan criou um grupo para repercutir os acontecimentos de Oitavo B e compartilhar informações sobre as atrizes Manoela Aliperti (Lica) e Giovanna Grigio (Samantha). A trama também era explorada no Twitter, através de sua conta pessoal na rede social a fã fazia enquetes solicitando a participação do público em questões como, por exemplo, quais músicas deveriam ser citadas pelas personagens, qual era o melhor dia para a publicação dos capítulos etc. Os leitores da fanfic usaram o microblogging para criar perfis fictícios dos personagens de Oitavo B. Como, por exemplo, o unicórnio mentor de Lica, Pedro Santiago, que aparece em suas alucinações, foi personificado no Twitter através do user 
leitura de segundo nível, o leitor semiótico-estético explora novas perspectivas da história, sempre mantendo a verossimilhança.

Um ponto interessante na construção da narrativa de Oitavo $B$ é a intertextualidade. Os elementos externos ao universo ficcional da telenovela são constantemente explorados por UmaOtaku-chan, uma fã e escritora de fanfics, autora de Oitavo B. Nesse sentido, a ironia intertextual, proposta por Eco (2002), propicia aos leitores uma experiência dinâmica com o texto, em que os acontecimentos, diálogos e desdobramentos são compostos por diversas camadas interpretativas.

A partir da análise das dimensões da competência midiática podemos refletir sobre o papel ativo dos fãs na construção de universos ficcionais que vão além do paratexto. Em outras palavras, ao expandir a trama na fanfic a fã reimagina os acontecimentos de Lica e Samantha a partir da colaboração, direta e indireta, do fandom. Dessa forma, as abordagens da história abrangem projeções e interpretações coletivas. Por fim, é fundamental destacar as idiossincrasias de cada grupo de fãs, ou seja, cada prática e fã terá modos de operação distintos em relação às dimensões da linguagem, ideologia e valores e estética.

\section{Referências}

ALVES, E. Fanfiction e práticas de letramentos na Internet. Campinas: Pontes Editores, 2015.

BACON-SMITH, C. Enterprising Women: Television Fandom and the Creation of Popular Myth (Contemporary Ethnography). Filadélfia: University of Pennsylvania Press, 1992.

BARTHES, R. S/Z. Lisboa: Edições 70, 1992.

BENNETT, L. Tracing Textual Poachers: reflections on the development of fan studies and digital fandom. Journal of Fandom Studies, [s. l.], v. 2, n. 1, p. 5-20, 2014.

BLACK, R. Language, Culture, and Identity in Online Fanfiction. E-Learning, [s. l.], v. 3, n. 2, p. $170-184,2006$.

BOOTH, P. (ed.). A Companion to Media Fandom and Fan Studies. Hoboken: John Wiley \& Sons, 2018.

BOOTH, P. Digital Fandom: New Media Studies. Nova York: Peter Lang, 2010.

COPPA, F. An archive o for own - Um arquivo só nosso (Escritores de Fanfiction, Uni-vos). In: JAMISON, A. Fic - Por que a fanfiction está dominando o mundo. Rio de Janeiro: Rocco, 2017, p. 295-304. 
DUFFETT, M. Understanding Fandom - An introduction to the study of media fan culture. Londres: Bloomsbury, 2013.

ECO, U. Sobre a literatura. Rio de Janeiro: Record, 2002.

EVANS, A; STASI, M. Desperately seeking methodology: New directions in fan studies research. Participations - Journal of Audience \& Reception Studies, Northumbria, v. 11, n. 2, p. 4-23, 2014.

FERRÉS, J; PISCITELLI, A. Competência midiática: proposta articulada de dimensões e indicadores. Lumina, Juiz de Fora, v. 9, n. 1, p. 1-16, 2015.

FISKE, J. The Cultural Economy of Fandom. In: LEWIS, L.A. (ed.). The Adoring Audience. Londres: Routledge, 1992. p. 30-49.

GRAY, J.; SANDVOSS, C.; HARRINGTON, C. L. (eds.) Fandom: Identities and Communities in a Mediated World. 2 ed. Nova York: New York University Press, 2017.

GRECO, C. TV Cult no Brasil: Memória e culto às ficções televisivas em tempos de mídias digitais. Tese (Doutorado em Ciência da Comunicação) - Escola de Comunicação e Artes. Universidade de São Paulo, 2016.

GROSSMAN, L. Apresentação. In: JAMISON, A. Fic - Por que a fanfiction está dominando o mundo. Rio de Janeiro: Rocco, 2017. p. 11-16.

HERRERO-DIZ, P. et al. Estudio de las competencias digitales en el espectador fan español. Palabra Clave, Chía, v. 20, n. 4, p. 917-947, 2017.

HILLS, M. Essential tensions: Winnicottian object-relations in the media sociology of Roger Silverstone. International Journal of Communication, [s. l.], v. 1, p. 37-48, 2007.

HILLS, M. Fan cultures. Nova York: Routledge, 2002.

HILLS, M. O fandom como objeto e os objetos do fandom. Matrizes, São Paulo, v. 9, n. 1, p. 147-163, 2015.

HIRSJÄRVI, I. Alfabetización mediática, fandom y culturas participativas. Un desafío global. Anàlisi Monogràfic, Barcelona, Espanha, [s. v.], n. 48, p. 37-48, 2013.

JACOB, M. C. et al. Entre novelas e novelos: um estudo das fanfictions de telenovelas brasileiras (2010-2013). In: LOPES, M. I. V. (org.). Por uma teoria de fãs da ficção televisiva brasileira. Porto Alegre: Sulina, 2015. p. 107-154.

JAMISON, A. Fic - Por que a fanfiction está dominando o mundo. São Paulo: Rocco, 2017.

JENCKS, C. The language of post-modern architecture. New Haven: Yale University Press, 1977.

JENKINS, H. Cultura da convergência. 2. ed. São Paulo: Aleph, 2008. 
JENKINS, H. Invasores do Texto - Fãs e cultura participativa. Rio de Janeiro: Marsupial Editora, 2015.

JENKINS, H. Lendo criticamente e lendo criativamente. Matrizes, São Paulo, v. 9, n. 1, p. 11$24,2012$.

JENKINS, H. Textual poachers: television fans and participatory culture. Nova York: Routledge, 1992.

JENKINS, H.; et al. Confronting the Challenges of Participatory Culture Media Education for the 21st Century. Massachusetts: The MIT Press, 2009.

JENSON, J. Fandom as Pathology: The Consequences of Characterization. In: LEWIS, L. A. (ed.). The Adoring Audience. Londres: Routledge, 1992. p. 9-29.

LUKE, A. Allan Luke: The New Literacies. The Learning Exchange, Online, 2007.

MALHAÇÃO: viva a diferença. Direção de Cao Hamburger. São Paulo: Rede Globo, 20172018. Telenovela. color.

NYAH! Fanfiction. Disponível em: https://fanfiction.com.br/. Acesso em: 26 jul. 2019.

PRIMO, A. $O$ aspecto relacional das interações na Web 2.0. E-compós, [S. l.], v. 9, p. 1-21, 2007.

SANDVOSS, C. Fans: the mirror of consumption. Malden: Polity Press, 2005.

SANDVOSS, C; GRAY, J; HARRINGTON, L. Introduction: Why Still Study Fans?. In: GRAY, J.; SANDVOSS, C.; HARRINGTON, C. L. (eds.). Fandom: Identities and Communities in a Mediated World. 2. ed. Nova York: New York University Press, 2017. p. 8-32.

SCOLARI, C. Literacia transmedia na nova ecologia mediática - Livro Branco. Barcelona: Europen Union Funding for Research \& Innovasion, 2018.

SIGILIANO, D; BORGES, G. The X-Files: uma análise das estratégias de social TV do perfil @thexfiles. Comunicação, Mídia e Consumo, São Paulo, v. 13, n. 39, p. 1-22, 2017.

SPIRIT fanfics e histórias. Disponível em:https://www.spiritfanfiction.com Acesso em: 22 jul. 2019.

THOMAS, A. Blurring and Breaking through the Boundaries of Narrative, Literacy, and Identity in Adolescent Fan Fiction. In: MICHELE, K.; COLIN, L. (eds). A new literacies sampler. Nova York: Peter Lang Publishing, 2017. p. 137-166.

TIROCCHI, S. Wattpad. In: SCOLARI, C. (ed.). Adolescentes, medios de comunicación y culturas colaborativas - Aprovechando las competencias transmedia de los jóvenes en el aula. Barcelona: H2020 Research and Innovation Actions, 2018. p. 99-104. 
UMAOTAKU-CHAN. Oitavo B. Spirit Fanfics e Histórias, Online, 2018. Disponível em: https://www.spiritfanfiction.com/historia/oitavo-b-limantha-11900691. Acesso em: 11 ago. 2019.

VERMOREL, F. Starlust: Secret Life of Fans. Nova York: Comet, 1985.

VIEIRA, V. Sucesso de audiência, Malhação volta a ser exportada após 13 anos; confira a versão em espanhol. 0 TV Foco. 19 jan. de 2018.

\title{
The fan as an aesthetic reader: an analysis of the dimensions of media competence in the fanfic Oitavo B de Malhação - viva a diferença
}

\begin{abstract}
When creating fanfics, fans develop writing and communication strategies related to multimodal and multimedia content, in addition to new textual forms of network conversation. This textual and intertextual reading of the avid audience establishes a clear dialogue with the concept of semiotic / aesthetic reader by Eco, in which the plots explore various interpretive layers and go beyond the paratext. Based on this theoretical contribution, this article aims to analyze the dimensions of media competence, proposed by Ferrés and Piscitelli, which are part of the fanfic Oitavo B. Published on the Spirit fanfics e histórias platform, the story resignifies the characters' narrative arc Lica (Manoela Aliperti) and Samantha (Giovanna Grigio), from Malhação - viva a diferença (2017-2018, Rede Globo). It is concluded that the fanfic not only reinforces and expands the children's soap opera, but establishes new interpretive ties.
\end{abstract}

\section{Keywords}

Fan Culture; Media Competence; Semiotic/Aesthetic Reader; Fanfic; Malhação

\section{Autoria para correspondência}

Daiana Sigiliano

daianasigiliano@gmail.com 


\section{Como citar}

SIGILIANO, Daiana; BORGES, Gabriela. O fã como leitor estético: uma análise das dimensões da competência midiática na fanfic Oitavo B de Malhação - viva a diferença. Intexto, Porto Alegre, n. 52, e100378, jan./dez. 2021. DOI: http://dx.doi.org/10.19132/1807-8583202152.100378

Recebido em 07/02/2020

Aceito em 27/07/2021

(c) $(1)(9)$ 